\title{
Constructional requirements and classification of nucleonic gauges
}

\author{
J. D. R. L. Gomes ${ }^{a}$, M. L. L. Costa ${ }^{a}$, R. S. Gomes ${ }^{a}$, E. L. C. Costa ${ }^{a}$ Z. D. Thoméb, \\ G. H. F. Caldas ${ }^{\mathrm{a}}$ \\ ${ }^{a}$ Comissão Nacional de Energia Nuclear/Diretoria de Radioproteção e Segurança Nuclear, 22290-901, Rio de Janeiro, \\ RJ, Brasil \\ ${ }^{b}$ Instituto Militar de Engenharia/Seção de Engenharia Nuclear, 22291-270, Rio de Janeiro, RJ, Brasil
}

jlopes@cnen.gov.br

\begin{abstract}
There are several hundred of nucleonic gauges installed in at least 500 industrial facilities in Brazil. In recent years, several standards have been issued by different international committees in order to specify requirements for the design of nucleonic gauges taking into account issues related to radiological protection. The aspects of design and manufacturing of these devices using radioactive sources should be treated as an important feature to an adequate safety approach during the whole operational life, mainly taking into account the extreme conditions of the places where the devices are installed. Thus, the agreement with these standards should be included as part of the equipment specification to the licensing process, however, most nucleonic gauges were installed in the period prior to the issuance of these international standards. In this work was studied the performance of shielding design taking into account international standards concerning the constructional requirements and classification of gauges. In view of the specific operational conditions found at reference facilities, the measurements obtained will be used for validation of a Monte Carlo code based on Geant 4 to allow extrapolations for other operational conditions. The results obtained in this study can enable the establishment of a safety indicator tool to industrial facilities, taking into account different designs, so that this additional parameter can be used to determine and to optimize the frequency of regulatory inspections.
\end{abstract}

Keywords: Nucleonic gauges, Constructional requirements, Geant4.

ISSN: 2319-0612

Accept Submission 2019-01-16 


\section{INTRODUCTION}

Nucleonic gauges (or radiometric gauges) have been widely used in industrial facilities with the purpose of monitoring and optimizing the industrial process, as well as controlling the quality of products. The operation of such devices is based on the transmission of the radiation emitted by one or more sealed radioactive sources, generally ${ }^{137} \mathrm{Cs},{ }^{241} \mathrm{Am},{ }^{85} \mathrm{Kr}$ or ${ }^{60} \mathrm{Co}$. X-ray generators and neutron sources can also be used on nucleonic gauges.

Nucleonic gauges began to be used more than fifty years ago. Since then, there has been a continuous growth in its use, being used in more and more areas of process engineering. They are no longer used only for level detection and continuous level measurement under extremely difficult measuring conditions, but also for interface, density and concentration measurement in connection with toxic or abrasive liquids, for mass flow measurement, such as on dredgers, or as belt weighers for throughput measurement in mines [1]. This means more and more facilities are using these devices.

Estimates by the International Atomic Energy Agency pointed out the existence of about 250.000 nucleonic gauges, from different manufacturers and different conceptions, installed in the world at the beginning of this century [2]. In Brazil, there are several hundred of these devices installed in at least 500 industries, mainly in the petrochemical areas, ore beneficiation, cement, aluminum manufacturing, steel, beverages, textile, paper and cardboard.

This equipment can be installed in areas that can be occupied by employees, so if radiation sources used in nuclear meters are not adequately shielded or handled in disagreement with operating procedures, the doses close to them may, in general, pose a significant hazard to health. In many facilities, the equipment is subject to extreme environmental conditions such as high temperatures, salinity, humidity and atmosphere with explosive gases.

In recent years, several standards have been issued by different international committees in order to specify requirements for the design of nucleonic gauges, taking into account issues related to radiological protection [3] [4] [5] [6]. The aspects of design and manufacturing of these devices should be treated as an important feature to an adequate safety approach during the whole operational life of this kind of equipment, mainly taking into account the extreme conditions of the places where the devices are installed. 
Nowadays, the licensing process is conducted using generic CNEN safety standards [7] [8] [9], However, the agreement with international standards should be included as part of the equipment specification to the licensing process these facilities.

\section{METHODOLOGY}

\subsection{Nucleonic Gauges Designs}

This work aims to evaluate nucleonic gauges with embedded ${ }^{137} \mathrm{Cs}$ radioactive sources, so initially, it was performed a survey in the CNEN's database regarding to models of radiometric gauges installed in Brazil. It was possible to conclude that the amount of equipment in use today at industrial facilities is dominated by designs of a domestic manufacturer, whose production was discontinued, as well as the presence of an important amount of imported equipment.

Figure 1: Nucleonic gauges installed at radioactive industrial facilities in Brazil. (Source: Authors)
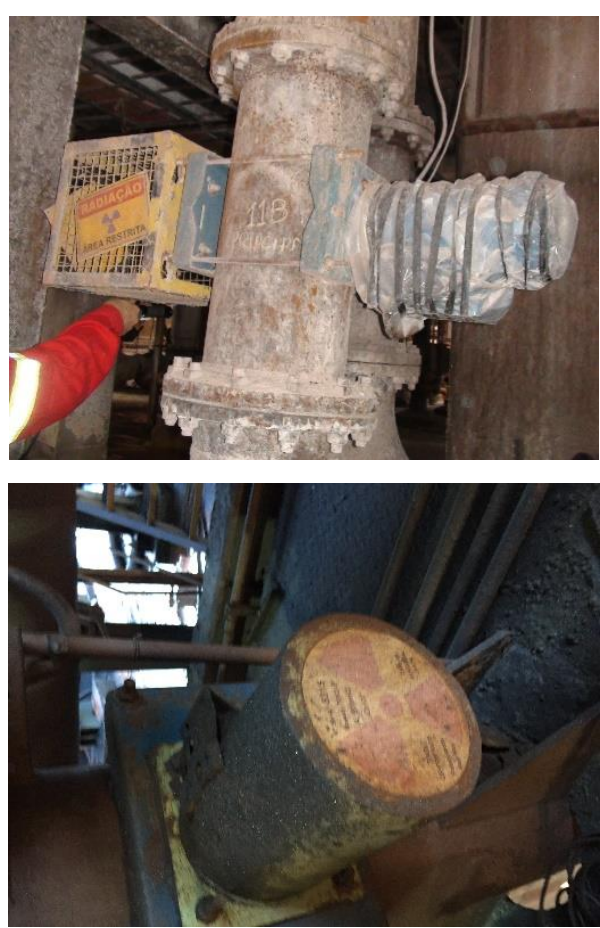
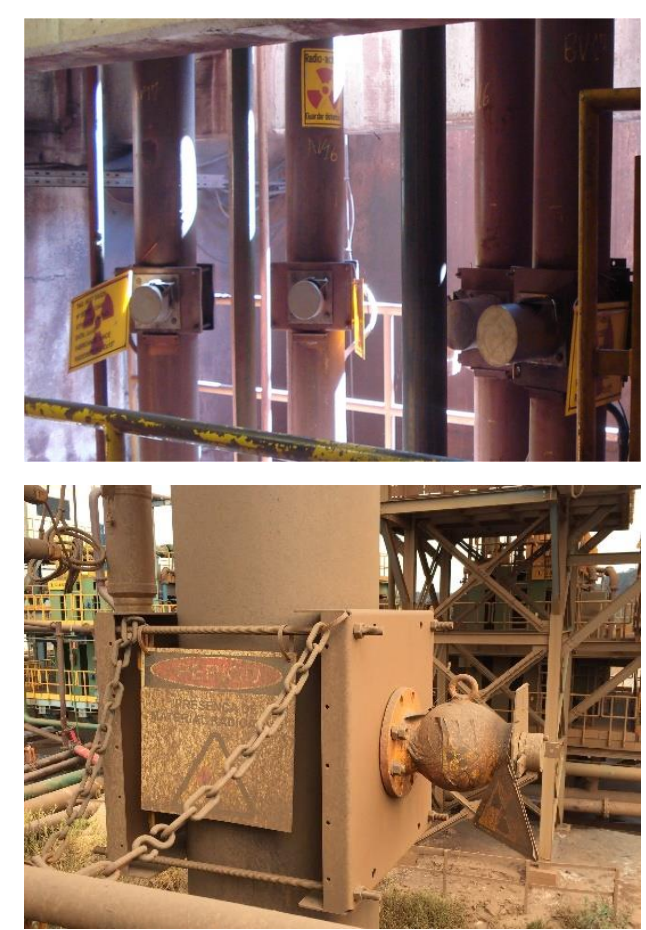
It was selected and modeled for Monte Carlo simulation the schematic drawings and technical data of the designs of main models of nucleonic gauges installed in Brazilian industrial facilities. Thus, seven different designs of nucleonic gauges were modeled and simulated using Geant4. They were identified in thus study by one letter $(\mathrm{A}, \mathrm{B}, \ldots$ and $\mathrm{G})$, as shown in figures 2 to 8 .

Figure 2: Modelling on Geant4 and schematic drawing of nucleonic gauge A (distances in mm).
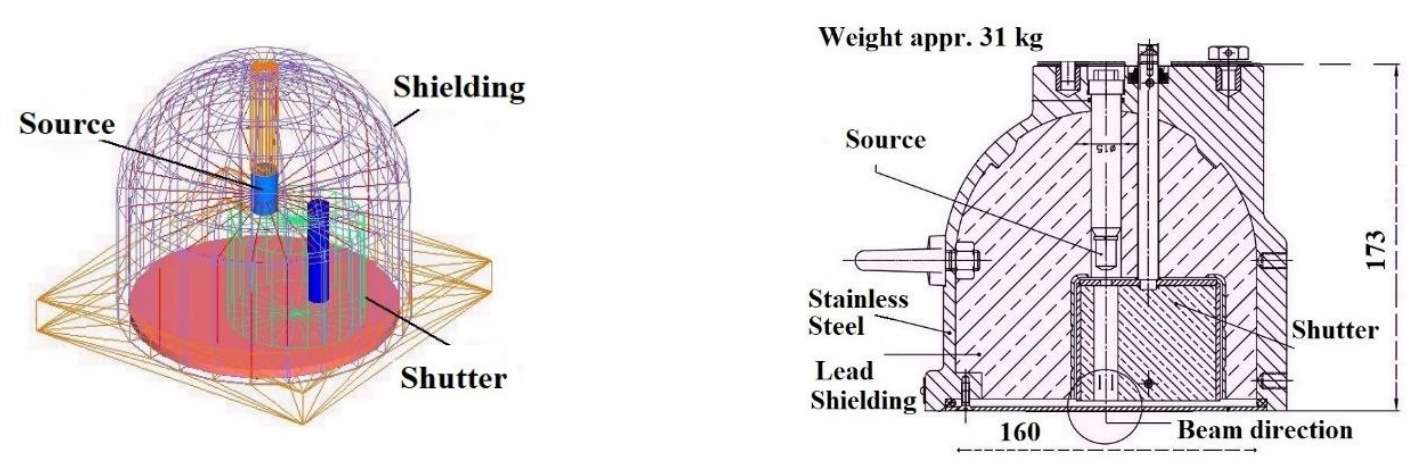

Figure 3: Modelling on Geant 4 and schematic drawing of nucleonic gauge B (distances in mm).
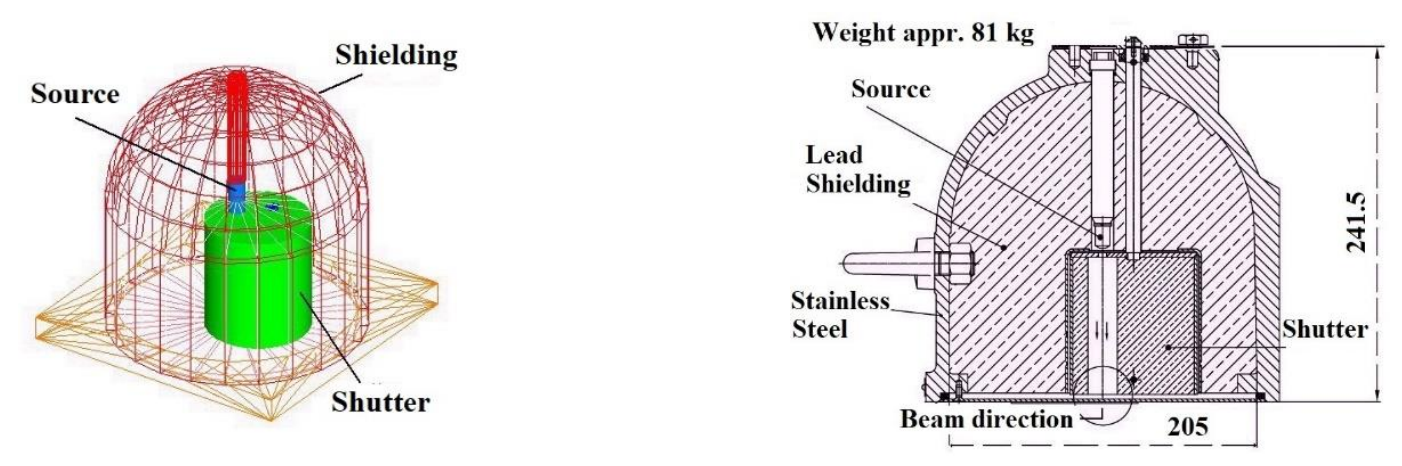

Figure 4: Modelling on Geant4 and schematic drawing of nucleonic gauge C (distances in mm).
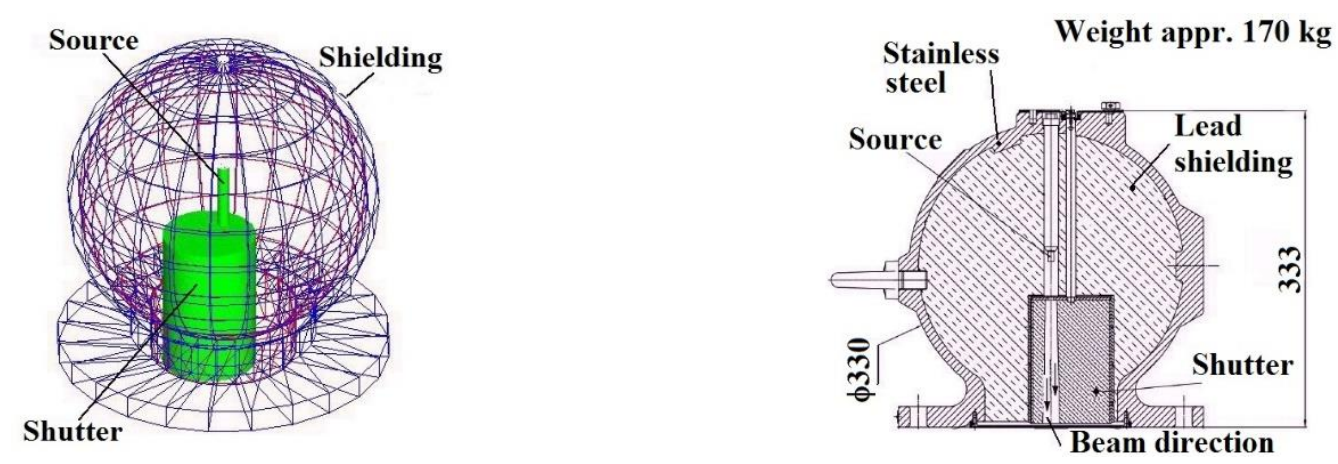
Figure 5: Modelling on Geant4 and schematic drawing of nucleonic gauge D (distances in mm).
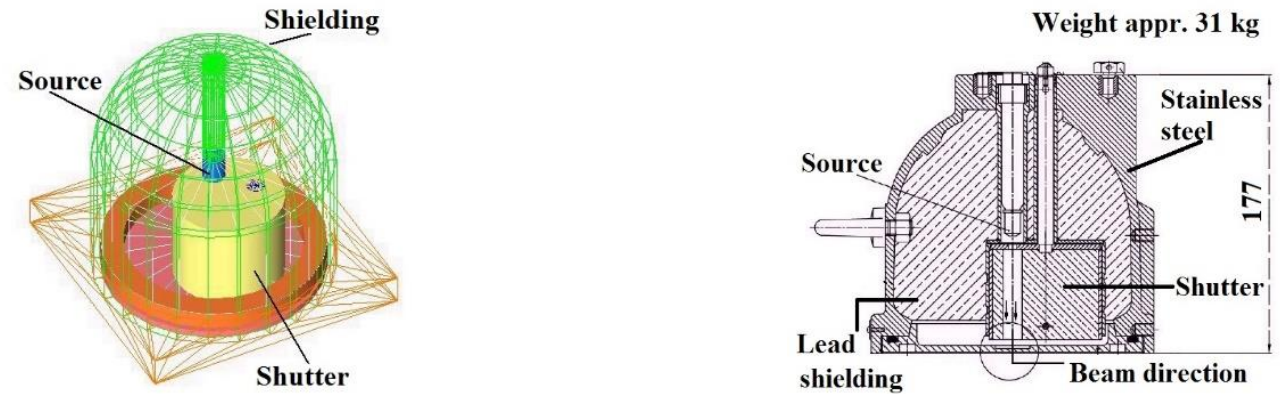

Figure 6: Modelling on Geant 4 and schematic drawing of nucleonic gauge $\mathrm{E}$ (distances in $\mathrm{mm}$ ).
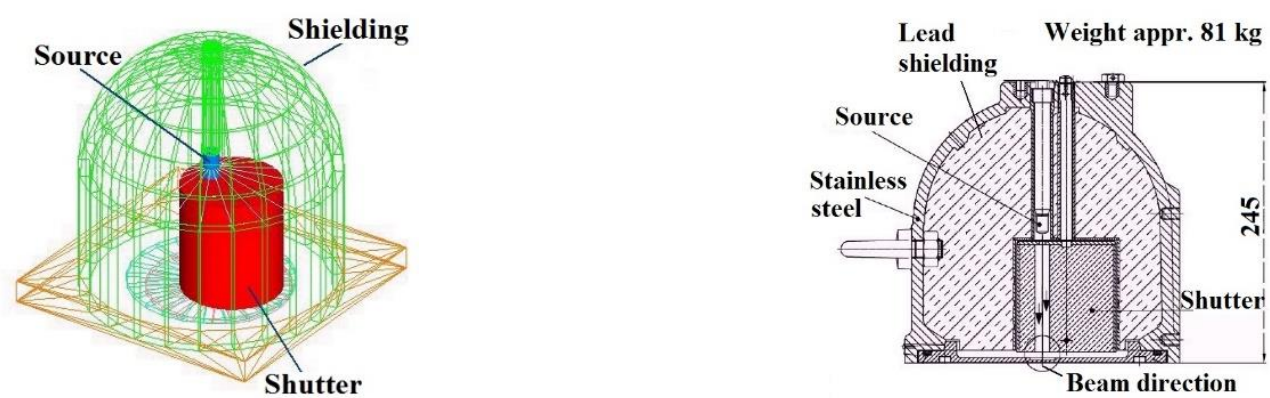

Figure 7: Modelling on Geant 4 and schematic drawing of nucleonic gauge $\mathrm{F}$ (distances in $\mathrm{mm}$ ).
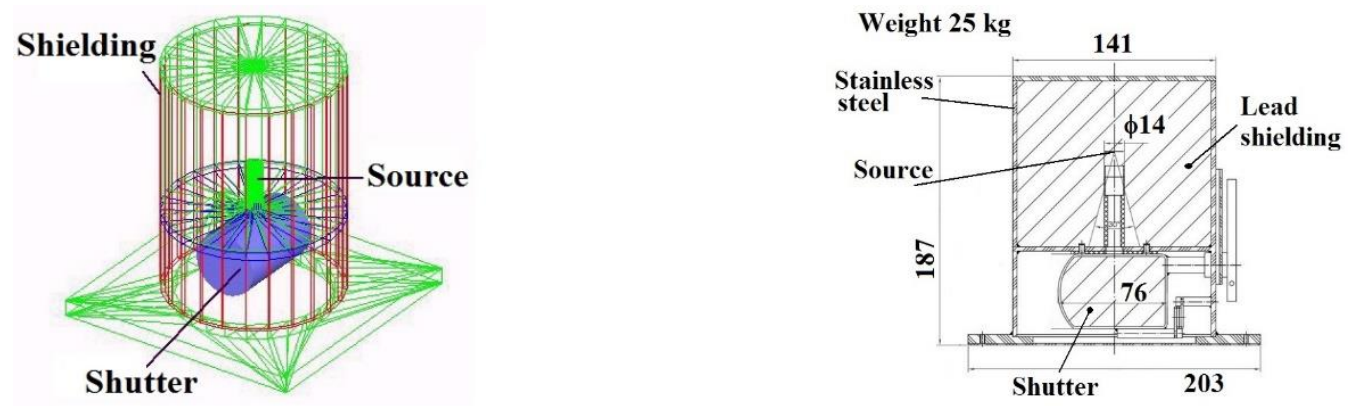

Figure 8: Modelling on Geant4 and schematic drawing of nucleonic gauge $\mathrm{G}$ (distances in $\mathrm{mm}$ ).
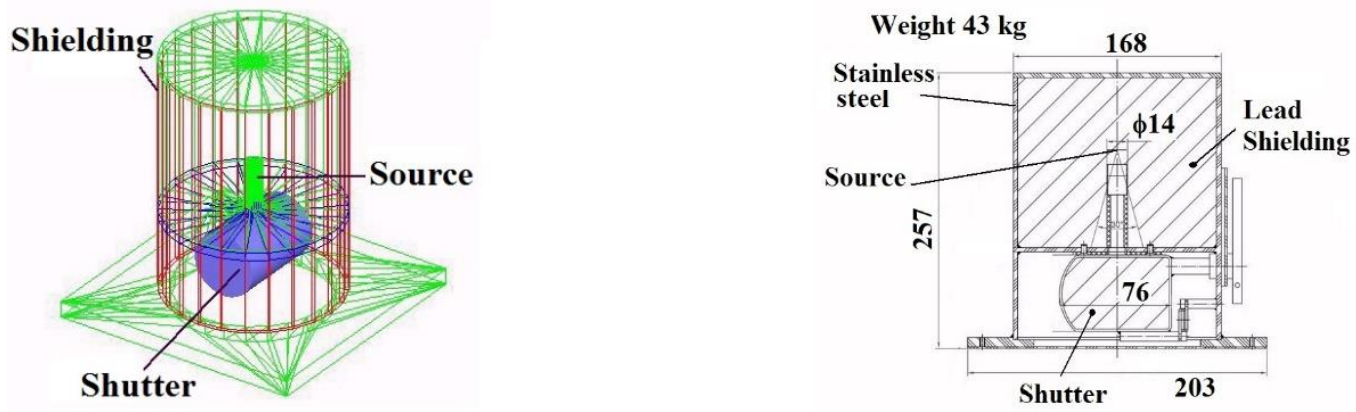


\subsection{International Standards}

It was studied the performance of each shielding design with the simulation of equivalent dose rate during normal operation at different distances from the equipment surface, with the shutter in open and closed status, taking into account international standards concerning the constructional requirements and classification of nuclear gauges [6], as shown in the figure 9.

Figure 9: Schematic representation of isodistance gauging faces

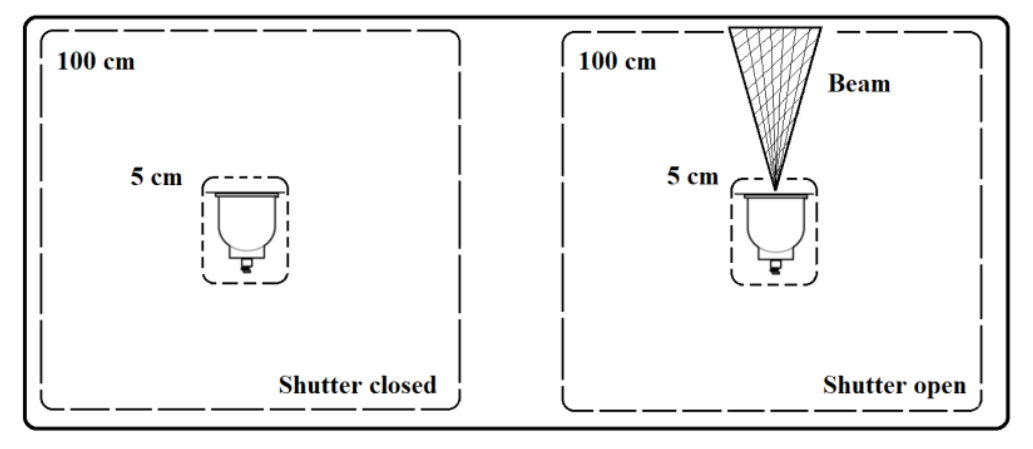

In the table 1 it is presented the categorization of nuclear gauges according its dose rates at different distances. It should be noted that the international standard IEC 62598 propose a classification code with four numbers indicating the gauge category, taking into account the dose rate class, as shown in figure 10 .

\subsection{Geant4 Simulation Process}

The simulations were performed using Geant4, a Monte Carlo program developed at CERN (European Organization for Nuclear Research) to simulate the interaction of particles and radiations with matter. The physical processes defined in the code cover electromagnetic and hadronic interactions over a wide energy range, from a few $\mathrm{eV}$ to $\mathrm{TeV}$, and are used in a large number of experiments and projects and in a wide variety of applications, including high particle physics, nuclear physics, astrophysics and radioprotection.

The physical processes in Geant 4 must be associated to the simulated particles and radiations. This configuration is managed by the PhysicsList module, which is a set of physical interaction models 
and cross sections, allowing the user to find the best balance between computation time and accuracy of simulated results.

All physical process involves two distinct phases: The calculation of cross sections and the generation of the final state. Both phases are based on data libraries providing relevant data to the Geant 4 Low Energy Process [10].

Table 1: Dose rate class of nucleonic gauges according IEC 62598, taking into account the distance from the surface of the nucleonic gauges.

\begin{tabular}{|c|c|c|c|c|c|c|c|}
\hline & \multicolumn{7}{|c|}{ Dose rate class } \\
\hline & 1 & 2 & 3 & 4 & 5 & 6 & 7 or $E$ \\
\hline $\begin{array}{l}\text { Maximum } \\
\text { equivalent }\end{array}$ & Not in & $>1 \mathrm{mSv} / \mathrm{h}$ & $>0,5 \mathrm{mSv} / \mathrm{h}$ & $>0,05 \mathrm{mSv} / \mathrm{h}$ & $>7,5 \mu \mathrm{Sv} / \mathrm{h}$ & $>3,0 \mu \mathrm{Sv} / \mathrm{h}$ & $\leq 3,0$ \\
\hline $\begin{array}{c}\text { dose rate at } \\
5 \mathrm{~cm}\end{array}$ & compliance & $\leq 5 \mathrm{mSv} / \mathrm{h}$ & $\leq 1 \quad \mathrm{mSv} / \mathrm{h}$ & $\leq 0,5 \mathrm{mSv} / \mathrm{h}$ & $\leq 0,05 \mathrm{mSv} / \mathrm{h}$ & $\leq 7,5 \mu \mathrm{Sv} / \mathrm{h}$ & $\mu \mathrm{Sv} / \mathrm{h}$ \\
\hline
\end{tabular}

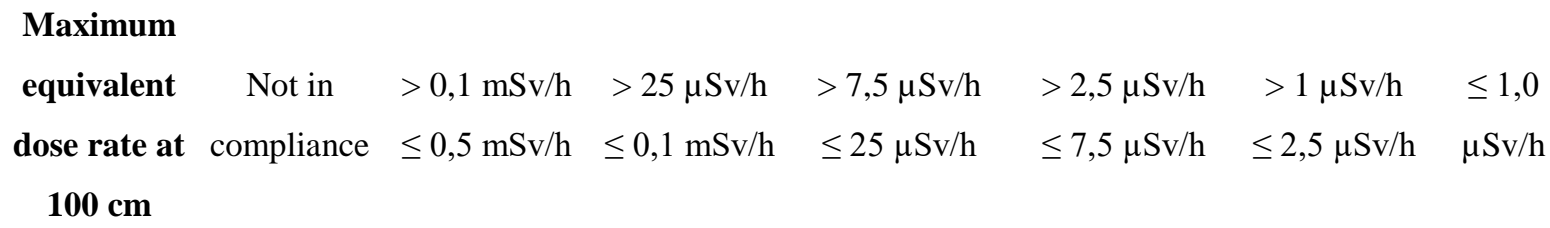

In this current work was used the G4EmLivermore PhysicsList, which provides low energy process validated for energies from $250 \mathrm{eV}$ up to $100 \mathrm{GeV}$ and the low energy limit to produce secondaries particles during the simulation (cut-off energy) was set to $250 \mathrm{eV}$, corresponding to the limit of validity of the physics models.

The simulated ${ }^{137} \mathrm{Cs}$ radioactive source of nucleonic gauges was defined was a point source using Geant4 General Particle Source module, and it was generated $2.5 \times 10^{7}$ histories, divided in five event runs, with different seeds values, for each gauge model and for each shutter configuration (open or closed).

The maximum equivalent dose rate was obtained in twelve positions around the nucleonic gauge at distances of 5 and $100 \mathrm{~cm}$ from the surface of the equipment. Therefore, for each position was set 
small volumes of tissue-equivalent material (G4-A150_Tissue material) with circular area of 100 $\mathrm{cm}^{2}$, according IEC International Standard [6], and thickness of $1 \mathrm{~cm}$, where the energy deposited was accumulated into a scoring variable and then divided by the mass of the volume material.

Figure 10: Classification code with four numbers, according to IEC 62598 Standard.

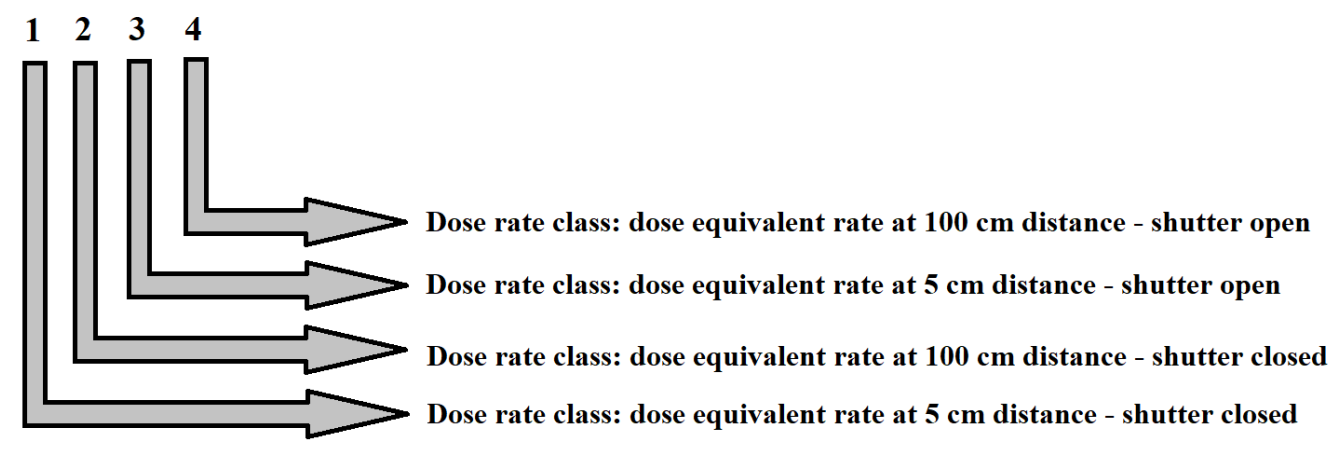

\section{RESULTS AND DISCUSSIONS}

The maximum dose rate of each nucleonic gauge design was obtained with Geant 4 simulations, taking into account the beam shutter configuration, open or closed, and the distance from surface of equipment. Thus, the equivalent class, according international standards, for each model could be defined, as shown in table 2 .

Table 2: Dose rate class of each simulated nucleonic gauge model, taking into account different shutter configuration and distances from the surface of the equipment.

Dose Rate Class

\begin{tabular}{ccccccccc}
\hline Position & Shutter & 1 & 2 & 3 & 4 & 5 & 6 & 7 \\
\hline $5 \mathrm{~cm}$ & closed & - & - & F & A, D, G & - & B & C, E \\
$5 \mathrm{~cm}$ & open & - & F, G & - & A, D & B, E & - & C \\
$100 \mathrm{~cm}$ & closed & - & F & - & - & G & D & A, B, C, E \\
$100 \mathrm{~cm}$ & open & - & - & F, G & B & A, D & - & C, E \\
\hline
\end{tabular}


Taking into account the dose rate class and according international standard, the gauge category code with four characters, obtained for each gauge design, is shown in table 3.

Table 3: The gauge category code

\begin{tabular}{cc}
\hline Nucleonic Gauge & Category Code \\
\hline A & 4745 \\
B & 6754 \\
C & 7777 \\
D & 4645 \\
E & 7757 \\
F & 3223 \\
G & 4523 \\
\hline
\end{tabular}

It should be emphasized that the IAEA recommends inspection frequencies between 3 and 5 years for nuclear gauges facilities [11]. The results obtained in this study can enable the establishment of a safety indicator tool, so that this additional parameter can be used to determine and to optimize the frequency of regulatory inspections at these facilities, based on their dose rate categorization.

It should be emphasized that this methodology can conclude that other designs, to be evaluated in the future, should be decommissioned once nucleonic gauges classified as dose rate class 1 are not in compliance with international standards.

Using the methodology as a safety tool for optimize regulatory inspections, it can be proposed:

- Facilities using $\mathrm{F}$ and $\mathrm{G}$ models must undergo regulatory inspections in a shorter time interval;

- A, B, D and E models could be inspected in time intervals between 3 and 4 years;

- C models could be inspected every 5 years.

\section{CONCLUSION}

The aspects of design and manufacturing of nucleonic gauges should be treated by the regulatory agencies, as well as by the operators, as an important feature to an adequate safety approach during the whole operational life of the equipment. 
Based on the results obtained in this study, it was concluded that the proposed safety tool is an adequate indicator to the evaluation of facilities using radiometric gauges, assisting the regulatory decision-making process in order to ensure the adequate safety, creating an additional parameter which can be used to determine and to optimize the frequency of regulatory inspections at these facilities, as well as, to decommission radiometric gauges not in compliance with international standards.

It should be emphasized that this proposed safety tool should not be used in isolation to assess the safety of a particular facility. In the next step, experimental measurements will be performed in reference facilities and they will be used for the validation of the tool, thus, situations beyond normal conditions observed in the reference facilities may be estimated, with the objective of characterizing the maximum capacity of each nucleonic gauge model, taking into account the new standards, as well as, accident conditions.

\section{REFERENCES}

1. BONATH, R. Nucleonic Measurement, Process Online, Wahroonga, 2010. Available at: $<$ http://www.processonline.com.au/content/instrumentation/article/nucleonic-measurement327001424/>. Last accessed: 21 Dec. 2017.

2. IAEA - International Atomic Energy Agency. Technical data on nucleonic gauges, IAEA TECDOC-1459, Vienna, 2005. 120p.

3. ISO - International Organization for Standardization. Radionuclide gauges - Gauges designed for permanent installation, ISO 7205, Geneva, 1986. 24p.

4. IEC - International Electrotechnical Commission. Nuclear instrumentation - Density gauges utilizing ionizing radiation - Definition and test methods, IEC 60692, Geneva, 1999. 35p.

5. ANSI - American National Standard Institute. Classification of industrial ionizing radiation gauging devices, ANSI N43.8, Washington, D.C, 2001. 28p. 
6. IEC - International Electrotechnical Commission. Nuclear instrumentation - Constructional requirements and classification of radiometric gauges, IEC 62598, Geneva, 2011. 48p.

7. CNEN - Comissão Nacional de Energia Nuclear. Diretrizes Básicas de Radioproteção. CNENNN-3.01, CNEN, Rio de Janeiro, 2014. 22p.

8. CNEN - Comissão Nacional de Energia Nuclear. Serviços de Radioproteção. CNEN-NE-3.02, CNEN, Rio de Janeiro, 1988. 17p.

9. CNEN - Comissão Nacional de Energia Nuclear. Licenciamento de Instalações Radiativas. CNEN-NN-6.02, CNEN, Rio de Janeiro, 2014. 14p.

10. CERN - European Organization f or Nuclear Research - CERN-OPEN-034. Geant4 Low Energy Electromagnetic Models for Electrons and Photons, CERN, Geneva, 1999. 11p.

11. IAEA - International Atomic Energy Agency. Inspection of radiation Sources and Regulatory Enforcement, IAEA TECDOC-1526 Vienna, 2007. 131p. 